\title{
Mechanism of Intraplate Earthquakes and Anthropogenic Causes in USA
}

\author{
Marilia Hagen \\ Department of Geological Sciences, Indiana University, Bloomington, USA \\ Email: mariliadtavares@gmail.com
}

Received 25 August 2015; accepted 22 September 2015; published 25 September 2015

Copyright (C) 2015 by author and Scientific Research Publishing Inc.

This work is licensed under the Creative Commons Attribution International License (CC BY). http://creativecommons.org/licenses/by/4.0/

(c) (i) Open Access

\begin{abstract}
In this paper we carried out an investigation about the possible causes for the enhancement of earthquakes in USA the last seven years. Our statistical and physical models indicated that the increased evolution of events in the country depends from the human actions. For further analysis we divided the country into three main seismological regions: western, central and, eastern. We roughly classified the areas by their thickness of Earth's crust in a variation $25-45-25 \mathrm{~km}$. The thickest area is in the mid-continent and most of this region are part of the Great Plains. In our study we are going to investigate the reason for the Mississippi Lime in Oklahoma a very thick area, started an unusual earthquake activity since 2010 , most at 0 klahoma/Kansas border. In this region also there are many anthropogenic activities concerning with the waste water wells and more than $\mathbf{4 0 0 0}$ of them are active in the state. Wastewater disposal wells typically operate for longer duration and inject much more fluid than hydraulic fracturing, making them more likely to induce earthquakes. Enhanced oil recovery injects fluid into rock layers where oil and gas have already been extracted, while wastewater injection often occurs in never-before-touched rocks. Therefore, wastewater injection can raise pressure levels more than enhanced oil recovery, and thus increases the likelihood of induced earthquakes. Most injection wells do not trigger felt earthquakes. A combination of many factors is necessary for injection to induce felt earthquakes. These include the injection rate and total volume injected; the presence of faults or unknown fractures that are large enough to produce felt earthquakes; stresses that are large enough to produce earthquakes; and the presence of pathways for the fluid pressure to travel from the injection point to faults. Finally other causes of human action triggering earthquakes fluid injection, hydraulic fracturing, enhanced oil recovery, mining, nuclear explosions, some of them will be mentioned and investigated in this paper. We also intend to explain why not all the waste wells are triggering earthquakes and how it would be strongly attached to the unevenness of the Earth's crust.
\end{abstract}

\section{Keywords}

Intraplate, Earthquakes, Waste Water Wells, Earth's Crust 


\section{Introduction}

Historic examples of intraplate earthquakes include those in 2011 in Mineral, Virginia (estimated magnitude 5.8) and, Oklahoma (magnitude 5.7), New Madrid in 1811 and 1812 (estimated magnitude as high as 8.1), the Boston (Cape Ann) earthquake of 1755 (estimated magnitude 6.0 to 6.3), earthquakes felt in New York City in 1737 and 1884 (both quakes estimated at about 5.5 magnitude), and the Charleston earthquake in South Carolina in 1886 (estimated magnitude 6.5 to 7.3 ). The cause of these earthquakes was often uncertain. In many cases, the causative fault is deeply buried, and sometimes cannot even be found. Under these circumstances it is difficult to calculate the exact seismic hazard for a given city, especially if there is only one earthquake in historical times. Some progress is being made in understanding the fault mechanics driving these earthquakes. Intraplate earthquakes also present significant seismic hazards, especially because they can affect densely populated regions with little preparation for seismic shaking. The existence of intraplate earthquakes remains a deep scientific mystery with strong societal implications that needs to be solved by innovative approaches. The current theory on intraplate earthquakes suggests that away from plate boundaries, earthquakes are often triggered when geological processes, such as the deposition and erosion of surface rock, alter the balance of opposing stresses subsurface rocks. Our research started in the earthquakes evolution with the available modern data in USA. The first period analyzed was for events $M \geq 4$ were a rare occurrence in the middle of USA during the period 1965-2015. However, the exception was in Oklahoma/Kansas which since 2010 increased the number of seismological events $M \geq 4$ and depth around $5 \mathrm{~km}$. The unusual behavior in Oklahoma State needed further clarification because some circumstances indicated as main cause the waste water wells or class II wells that increased in number since 2009. Therefore, we decide to investigate with more details the period 2009-2015 when this paper is being done. Although the oil and gas companies discourage research on this topic, it is worrying that at the moment, July 2015 is reported more than 124 events in the region with the range $M \geq 3.5$. We defined the region as mid-continent as the locations covered totally or partially by the Great Plains; they were Colorado, Kansas, Montana, Nebraska, New Mexico, North Dakota, Oklahoma, South Dakota, Texas and Wyoming. Those states are defined by the following coordinates: $30.06 ' \mathrm{~N},-97.48^{\prime} \mathrm{W}, 30.06$ 'S and $-95.76^{\prime} \mathrm{E}$. One peculiarity observed was that events $\mathrm{M} \geq 4$ happened only in Oklahoma during the period 2009-2015.

The peculiarity of earthquakes is connected with the locations, for example, in some areas quakes $M \geq 6$ are common, as the west side of USA. However, some regions are completely uneventful on the period analyzed, even though there are waste disposal wells there. There are cases that locations present cluster of earthquakes and no fracking, nor disposal wells.

In order to investigate a possible link between human influence and the enhancement of earthquakes in the middle of USA, we started searching for reliable records on the wells opened in last years in the USA. Our aim was mostly to distinguish the places that opened conventional and unconventional wells associated with waste water wells, mostly when they were wells for gas which released lots of salt water and needed to be discharged underground.

Unfortunately, the reliability of the wells data was limited; some were withdrawn, inactive, stopped working or just started pumping. Some companies did not release a complete information as kind of slant, if it was fractured or not fractured, and many had unknown shale formation. Nevertheless, it helps to guess how much waste water wells are being related because it is necessary to dispose the salty water as a sub product from coalbed methane extraction, for example. For the gas and oil wells data, we used EIA and FRAC FOCUS lately data. At the last moment, we found a Texas map displaying 7000 waste water wells and their location on the state. The same was published for Oklahoma which had 3000 waste water walls in a smaller area.

The data to earthquakes came from three catalogues: two of them with recent data 1965-2015, and one with historical data. They are USGS, IRIS, and NGDC/NOAA. The catalogues prioritize different kinds of data and by comparison it is possible to have an excellent view of each state.

Ellsworth [1] agreed that the number of earthquakes related to fracking had been on the increase and that the industries should monitor them better. It agrees with our observations in locations as Oklahoma as we are going to discuss later. McGarr et al. [2] made a study about the anthropogenic seismicity and described that in some regions manmade earthquakes were more obvious because background seismicity was low. Our research finds out that places as the midcontinent are easier to check out human activity than California coast.

McGarr [2] [3] studied the maximum magnitude earthquakes induced by fluid injection. He proposed a model to find out how large an earthquake induced by fluid injection or other methods could be. His conclusions point out that maximum seismic moments are limited based on the total volume injected in the environs of the induced 
earthquakes. Earthquakes occurring in spatial and temporal proximity to such operations as hydraulic fracture are immediately under suspicion to be triggered or induced. It is not a clear way to discriminate induced, triggered and natural seismicity but some researchers are trying to make clear rules and establish scientific methods on this purpose. Although those papers presented interesting and value ideas on the processes and the influence of unconventional wells or waste water disposals in the propagation and increase of earthquakes, they could not explain why in some regions it looked like the waste water wells were able to enhance the earthquakes and in other areas the waste disposal wells did not make any remarkable difference on the events.

\section{Great Plains, Main Faults}

United States can be divided in three main seismic regions the West, the Central region most formed by states in the Great Plains, and Eastern. These three areas have complete diverse geological formation, implying varied earthquakes characteristics as we are going to see.

The content of our work, are statistically data events by different catalogs in the same subject for earthquakes magnitude (small, medium, large), depth (shallow or deep), and special features as the known faults, at the western side San Andreas, and eastern side New Madrid, researching on earthquakes data will allow to know where there are more occurrences, which depths, the variations during the last seven years compared with the history since 1965, if the magnitude has increased, the frequency changed, and analyzing the variation in the depths. In order to search earthquakes activity and possible enhancement due to the unconventional drilling we defined a region in the mid-continent covered totally or partially by the Great Plains, they are Colorado, Kansas, Montana, Nebraska, New Mexico, North Dakota, Oklahoma, South Dakota, Texas and Wyoming. Those states are defined by the following coordinates: $30.06^{\prime} \mathrm{N},-97.48^{\prime} \mathrm{W}, 30.06^{\prime} \mathrm{S}$ and $-95.76^{\prime} \mathrm{E}$. One peculiarity observed was that events $M \geq 4$ happened only in Oklahoma during the period, 2009-2015. The states in the mid-continent belong to the Great Plains, parts of 10 states of the United States (Montana, North Dakota, South Dakota, Wyoming, Nebraska, Kansas, Colorado, Oklahoma, Texas, and New Mexico) and the three Prairie Provinces of Canada (Manitoba, Saskatchewan, and Alberta) and portions of the Northwest Territories are within the Great Plains proper. Shallow ocean waters covered a significant part of the interior of North America, including the region we recognize as the Great Plains, for most of Paleozoic and Mesozoic time. Typically between 5000 and 10,000 feet of layered sediments, predominantly limestones, shales, and sandstones representing a mixture of seafloor, near-shore, and delta environments, accumulated during the course of almost 480 million years. This long period of predominantly shallow marine deposition was brought to a close some 70 million years ago when a major period of mountain building (the Laramide Orogeny) created a belt of mountains stretching from Alaska to Mexico. This major shift in geologic processes lasted for more than 20 million years, as the continental seas retreated, to be replaced by the first landscapes of the ancestral Great Plains. At the western side of USA, earthquakes happened in higher numbers and magnitude near the San Andreas Fault, it covers California, Oregon and Washington, in the time 1965-2014 events $M \geq 7$ happened most at Northern California with two events in Los Angeles. Events $\geq 6$ happened in these states and also in Idaho, Utah, Nevada, Los Angeles and San Diego. We isolated Nevada since it showed a very high number of quakes $M \geq 6$. These events all happened at South of Nevada in the Amargosa desert. Many of such big events are not connected by natural causes and USGS catalog classified them as nuclear explosions, recently. Apparently, after 2005 in this area there were not more nuclear tests, therefore, the total records in the period 2009-2015 did not experience any earthquake above M5. Even it showed a decreasing in number of events, after 2006. Small magnitude clusters appeared in Northern Nevada. The Reno earthquakes of 2008, also known as the "Mogul-Somersett Earthquake Sequence", occurred in or near the western Reno, Nevada suburbs of Mogul and Somersett. The earthquake swarm began in February 2008, but the first significant quake of the series occurred on April 15, 2008, registering a 3.6 magnitude by Anderson et al. [4]. All those three big areas make a variation in the crust thickness that roughly follow, $25 \mathrm{~km}$ at Western side, $45 \mathrm{~km}$ at the Central USA, and $25 \mathrm{~km}$ at the Eastern side. At the first glance, we did not considered small variations in these crustal thicknesses. Inner USA many subsurface structures were formed by the uplifting in Oklahoma/Arkansas, unknown faults and fractures created when the area were opened by the shallow inner ocean. Human influences would be easier noticed at the mid-continent due the smaller number of catastrophic earthquakes in the area.

The eastern side during the early opening of the Atlantic Ocean in the Mesozoic Era has numerous extensional basins formed along the eastern margin of North American continent from Florida northward to New England and parts of adjacent Canada. This area has a mean unexploited natural gas resource of 110 billion cubic $\mathrm{m}$ and 
undiscovered natural gas liquids resource of 135 million barrels in continuous accumulations within five of the East Coast Mesozoic (Hennings et al. [5]). Waste wells started to become more popular in 2007 however the data collected about those wells just began in 2009 in some parts of the country. Our investigation concentrating on this period will be able to find out what changed in the environment following their locations in the country.

The last years have experimented an enhance of earthquakes in some States, as the ones affected by New Madrid fault, Missouri, Illinois, Indiana, Kentucky, Tennessee and, Arkansas which surround a huge seismic zone and witnessed frequently quakes $M \geq 4$ during the longer period analyzed 1965 to 2015 what is not observed in other midcontinent regions, exception Oklahoma/Kansas. The other big fault in USA, San Andreas Fault (western side) earthquakes with $M \geq 7$ are not uncommon near Los Angeles, California. Resuming each location investigated presented different responses if they are under the same parameters as pressure variation, stress, and the strain due the diverse geomorphic characteristics of each region. The objective of this research will be examine how fracking and the deep waste water wells would boost earthquakes in several different regions of the country or if it would be due to another causes.

The first part of this paper shows the local implications of pressure, strain and stress on the brittle rocks, without considering propagation of shock or pressure waves to fractures or faults. Nearby faults any kind of human action will influence the frequency and the depth of the earthquakes. To have a better idea about earthquakes enhancement is necessary to analyze as much available data not only the physical mechanisms responses which are limited by environment, space and time.

The second part, we worked with the several subject data and look for a possible link events/ human actions. We are most investigated places where a clear enhancement of events reached a Magnitude 4 or plus. In cases that earthquakes are small and detected by instruments one could justify saying that only some years ago, instruments are getting more seismological signs therefore for a statistical analysis is better to observe the places where occurred higher magnitude events that some years ago were unlikely.

Our first target was the midcontinent area where occurred a clear enhancement of quakes, isolating this area under the following coordinates: $48.22^{\prime} \mathrm{N}, 25.32^{\prime} \mathrm{S},-67.06^{\prime} \mathrm{E}$ and $-126.47^{\prime} \mathrm{W}$. Therefore the delimitation of this space allowed searching a possible connection between our variables and higher seismological activity. After this inspection we expanded the search in other regions of the country with similar enhancement of events but a possible human interference. One characteristic of the surge of artificial earthquakes it was they happened in small magnitude clusters in some areas where usually did not have events. Once a cluster was detected in the area, we looked for any natural cause and which kind of human exploitation in the area. Regarding to the wells it is important that the pressure and stress inside each well is transmitted to the subsurface fractures or faults nearby known, unknown and they are strongly dependent on the geological structures underground, those structures reliant in each location perhaps dormant fractures from the Cretaceous Seaway.

Many physical properties such permeability, viscosity, Young's modulus and thermal conductivity vary with porosity or fluid content in sediments and minerals. The porosity in turn depends on the deformation and compaction state and can be calculated from the compaction curves resulting from the proper compaction modelling. Therefore different shales composition will demand a specific study on the region to investigate the consequences of drilling. Our investigation covered the data about active oil and gas wells recorded most in 2014 with directional, horizontal slant, hydraulic fracture or not. Also search for the waste water disposal well, however this parameter is not really known in a national configuration, and it is nowadays most in Texas and Oklahoma mapping.

\section{Reservoirs}

A petroleum reservoir or oil and gas reservoir is a subsurface pool of hydrocarbons contained in porous or fractured rock formations. The naturally occurring hydrocarbons, such as crude oil or natural gas, are trapped by overlying rock formations with lower permeability.

Let's consider a reservoir formed in Alabama, Coneasauga, which formation is Cambrian, located at $1100 \mathrm{~m}$ depth with a thickness varying between $1400-4500 \mathrm{~m}$. Niobrara, is shale situated in Colorado, found at 915 $4300 \mathrm{~m}$ depth, which thickness is $90-1000 \mathrm{~m}$, in this case the structure is from Late Cretaceous. Both shales are examples of diverse structures which make them response differently under stress. The first one is near the Appalachian and the other partial covered by Great Plains, also important in our analysis. The shale formation seems to have an impact in the quakes, as for example the Bakken shale found at the depth $2750-3050 \mathrm{~m}$ whose reservoir thickness is circa $40-140 \mathrm{~m}$. 
Bakken shale located Montana/North Dakota, is a formation late Devonian and early Mississippian the earthquakes most happen around the second formation in Montana, and North Dakota indeed decreased events. It seems the shale located in a shallower depth, and thicker reservoirs attend more frequent earthquakes than ones with smaller thickness and deeper location.

Barnett shale, located on Texas had intense activity since 2009; all the earthquakes shown an epicenter located at $5 \mathrm{~km}$ depth around Dallas; however the magnitude of those events is smaller.

As the last point in our research we isolated the midcontinent region in Oklahoma and Kansas showing the earthquakes with higher Magnitude happened only in this region. Particularly it is part of the Mississippi lime and presenting clusters of earthquakes $M \geq 4$, most of them with depth at $5 \mathrm{~km}$.

The western side of USA is located at the boundary of two tectonic plates Pacific and North America the incidence of earthquakes are higher in magnitude and frequency due to the subduction zones, faults known and unknown, fractures and the thickness of the crust, which is $25 \mathrm{~km}$ in places as Baja California. The midcontinent embodies the Great Plains and the Earth's crust may reach $45 \mathrm{~km}$ is some points, and perhaps also has some unknown fractures in the places once was an ocean.

The eastern side of USA is different from the others two and it is far from the border of the tectonic plate which limits at the middle Atlantic ridge. The eastern side has faults as New Madrid where in the past occurred big earthquakes and it is stage of small earthquakes. Nowadays, in the states affected by New Madrid show higher number of earthquakes $M \geq 4$ occurring in greater depth. Here the crust thickness is highly varied and not many deep earthquakes or higher magnitude has been occurred historically, unless in New Madrid, and some other points already discussed.

\section{Calculations}

Our paper is divided in two parts first a physics model to explain eventual gaps into unconventional drilling and the consequent damage from the waste water wells made nearby. Our data took during 2009-2015 which is the time interval the construction of deep waste disposal wells enhanced. The data for earthquakes came from three diverse catalogs, one for fracking (conventional and non-conventional) and some others for the waste disposal wells. Most of our model is statistical what means to use some caution with the data displayed and the interpretation of them.

\section{Data Used on This Paper}

Before going forward it is required to make some remarks on the data, to avoid omissions, duplications or wrongful inclusion it was necessary to compare more than one catalogue. It also partially avoid physical variations, instrument drift, failure to account for a factor, incomplete data (from one or another catalogue), missed data, hidden data, classified data deliberated or not, instabilities on the measures. About the catalogs there are discrepancies between the numbers of events, the sets rarely matches with each other in the period of one year. In the period 2009-2015 only one year USGS reported higher number of documented events than IRIS (2010). They remained with different quantities on 2015. The data categorized as anthropogenic or different sources started to be classified and released, by USGS some years ago. On the other hand, several small earthquakes with depth zero were not reported by USGS, only IRIS had all of them recorded, though IRIS was unable to distinguish anthropogenic sources. USGS was the only source that classified data by depth, magnitude, and included the origin of the earthquake, such as landslide, explosion and rock bursts. Unfortunately, USGS and IRIS had several disagreements in the data displayed mostly for shallower or smaller earthquakes. All data used in this paper are statistical variations, Google maps, and the crust thickness variation published by USGS. This paper analyzed earthquakes that happened in USA since $1638(\mathrm{M} \geq 4)$. The first discovery was that the events followed outlined paths on the continent. Those routes moved onward in vertical or slope direction following the main faults. At the modern times (1965-2014), medium earthquakes had an enhancement along the same routes, smaller earthquakes $(\mathrm{M} \leq 3)$ happened broadly in the country and no special route was drawn. Those first results lead us to conclude that earthquake events depending of the location, most medium to strong magnitude. Therefore it is possible to divide the country in three regions following the roughly crust thickness we had. One map was constructed by Sandvol et al. [6] who created a database encompassing basic geologic information. These three regions are, western, central and, eastern, each of them behaving differently related to earthquakes. The middle of USA is dominated for a thickest crust in USA, which can reaches $45 \mathrm{~km}$ in some points, they are also covered most of the land by the Great Plains. 
Recently Hennings et al. discussed the relationship between stress, stress heterogeneity, and the permeability of subsurface fractures and faults. They analyzed a Sumatra region, Indonesia. They find out that reservoir potential is most enhanced in areas with large numbers of fractures with high ratios of shear to normal stress. This occurs in areas of the field that are in strike-slip stress style. Comparatively, reservoir potential is lower in areas of the field that are in a thrust-fault stress style where fewer fractures with high shear to normal stress ratios exist. Working on this direction we find out that many earthquakes happen near of some wellbores, and none happened near others. Therefore, it showed a clear connection between stress, stress variability, active faults, and the permeability of natural fracture systems in the subsurface.

\section{Physical Model}

The physical mechanism for hydraulic fracturing involves injecting mixture of water, sand, and chemical additives into a subsurface petroleum reservoir at high pressure. The initial stage of a well shows that small earthquakes would be caused due to strain to break the rocks to construct the well. Young's modulus, $E$, can be calculated by dividing tensile stress by the extensional strain in the elastic (initial, linear) portion of the stressstrain curve:

$$
E=(\text { tensile stress }) /(\text { extensional stress })=\sigma / \varepsilon=(F / A) /(\nabla L / L)
$$

where $E$ is the Young's modulus (modulus of elasticity);

$F$ is the force exerted on an object under tension;

$A$ is the original cross-sectional area through which the force is applied; $\Delta L$ is the amount by which the length of the object changes;

$L$ is the original length of the object.

The Young's modulus of a material can be used to calculate the force it exerts under specific strain.

$$
F=E A \nabla L / L
$$

where $F$ is the force exerted by the material when contracted or stretched by $\Delta L$.

Hooke's law can be derived from these formulas (1) and (2), which describes the stiffness of an ideal spring:

$$
F=(E A / L) \quad \nabla L=k x
$$

where it comes in saturation

$$
k=E A / L \quad \text { and } \quad x=\nabla L
$$

Young Modulus $(E)$ in Equation (1) is directly dependent on the pressure (strain) and brittle materials break under the applied pressure. Small induced earthquakes will happen by hydraulic fracturing when the pressure exerted into the well is enough to break brittle rocks (Frac Focus, 2014). The created fracture in the wells, induce small earthquakes, however, it is not the only problem rise. The hydrostatic pressure into the well will decrease because the level of oil and gas will decline on time. It depends from the fluid density (gas or oil), the acceleration of the gravity, and the fluid depth. There is a second and third recovery stage for wells when the production declines. It is possible that some earthquakes are triggered by such operations; the shallow depth for the events indicates a possible location for sub surface fractures nearby the shale or in the region of drilling.

Our model supposes a cylinder with walls covered with concrete with a vertical length between 1830 to 3050 $\mathrm{m}$ depth. The posteriori horizontal length is $2130 \mathrm{~m}$ long. Horizontal drilling involves deviating a vertical well bore along a curved path to intersect a reservoir in a near-horizontal plane. The bore is typically around $25-152$ $\mathrm{mm}$ diameter. Next, explosive charges are placed in the bore and set off to fracture the casing so that gas can get into the bore. In this phase of the process occur the induced earthquakes due the high pressure on the horizontal small holes. In some cases the pressure required is 30,000 to 40,000 horsepower that is a lot of energy being consumed. After the process of fracking, waste water is removed and need to be recycled or released because the contaminated compound including chemicals and radioactive elements. Increases in seismic activity following hydraulic fracking are caused by the deep-injection disposal of hydraulic fracturing flow back (a byproduct of hydraulically fractured wells) and produced formation brine (a byproduct of hydraulically fractured wells). Fracturing in rocks at great depth frequently becomes suppressed by pressure due to the weight of the overlying rock strata and the cementation of formation. Scientists nowadays, agree that this kind of disposal water is responsible for the enhancement of earthquakes on Central USA. However, they can't explain why only a small 
percentage of those wells look to have a higher impact in seismological events. In our research we observed that those events happened more often in some specific areas and one of their characteristics that make easier to find are the small magnitude cluster in those places. Apparently thicker crust region indicates smaller earthquakes magnitude. Thinner crust results events with higher magnitude as the western side of USA.

To corroborate these suppositions we isolated a region in the middle of USA studying the occurrence of events, with the follow coordinates: $-126.47^{\prime} \mathrm{W},-67.07^{\prime} \mathrm{E}, 48.22^{\prime} \mathrm{N}$ and 25.32 'S (Figure 1).

\section{Correlations Data and Physical Model}

Figure 1 shows the activity on USA for earthquakes magnitude $M \geq 6$ during the period 1965-2015. All of them happened at western side, many at California's Coast. Some events were nuclear explosions in Nevada according the USGS catalog. Most of those events had shallow depth or superficial $(0-1 \mathrm{~km})$. Those events happened all of them at the left side of Rocky Mountains.

In Central and East coast the events with higher magnitude last years (1965-2015) were one in Oklahoma and other in Virginia. Initially they were supposed to be due natural causes and unusual for their locations. Until 2009 seldom events happened in Central or Eastern regions with magnitude $M \geq 4$. In 2011, two remarkable events happened with approximately the same magnitude and the same depth in two different states, Virginia and Oklahoma. Virginia earthquake happened in the Richmond basin near Central Virginia, the Oklahoma event occurred near the Wilzetta fault; in both cases the reasons were not clear.

Oklahoma has a historical record of increasing number of events on the region between northeastern Oklahoma and central Kansas, events in this area start increased in frequency and magnitude since 2009, in a region named Mississippi Lime. Taking the name apart, the "Mississippian" refers to a geologic period roughly 320 to 360 million years ago. "Lime" refers to marine limestone laid down during the Mississippian when an inland sea covered parts of the North American continent. This thick limestone section does diverge slightly from other plays that have a bigger shale component as part of their interbedded zones. The oil and natural gas play of that name focuses on a specific part of this area centered along the Kansas/Oklahoma border, with some experts estimating it to extend as far as southern Nebraska. While the largest activity gas/oil has been in northern Oklahoma, areas now considered as part of the shale stretched farther north and west within Kansas. The number of earthquakes in Oklahoma in the period 2009-2015 has been enhanced in an area where seldom events reached $\mathrm{M} \geq$ 4 until 2010. A special event happened in 2011 which magnitude reached 5.7, although some scientists pointed out it was probably due the human activity nothing was really proved.

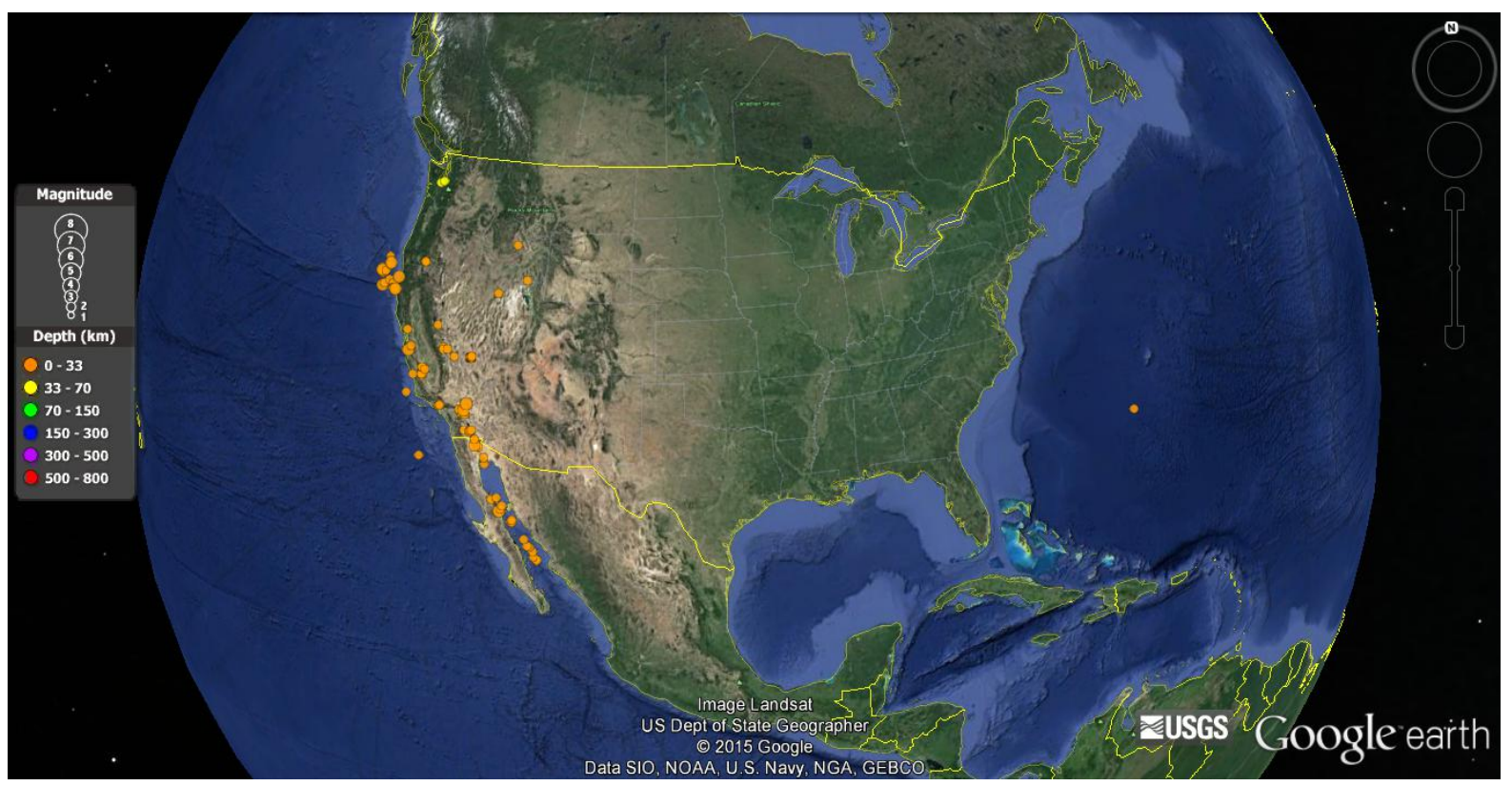

Figure 1. Events occurred 1965-2015 with magnitude $M \geq 6$ in USA. It most happened at the western country side, near subduction, fault zones and thinner Earth's crust areas. 
A similar event happened in Virginia, in the Richmond basin, one of the oldest cold bed methane exploitation. The 2011 quake along with dozens of others in the Raton Basin of Colorado and New Mexico was caused by a byproduct of coalbed methane extraction. The culprit is coalbed methane extraction or, more specifically, the wastewater it produces. Coalbed methane is a natural gas trapped in the seams of coal deposits, and when it is sucked from the earth it brings up huge quantities of water so salty that is illegal to dispose of above ground [7]. Therefore, it is drill deeper wells, up to 1, 5 kilometers down, to inject the water into deeper geologic formations. However, at those depths there are unknown natural faults, when the water injected will increase the pressure reducing the strength and makes the faults lines less damped together. All in all, that leads to earthquakes. Rubinstein and others have made the strongest argument yet that some wastewater injection wells do in fact, cause the earth to slip and slide [8].

Figure 2 is showing the occurrences of earthquakes $M \geq 5$ and $M \leq 6$ with the same coordinates as Figure 1 in the period 2009-2015. This figure displays some events western, central and eastern side, including the ones in Oklahoma and Virginia.

If we are narrowing the coordinates on Mississippi Lime, $40.21^{\prime} \mathrm{N}, 33.54 ' \mathrm{~S},-94.02^{\prime} \mathrm{E},-98.51^{\prime} \mathrm{W}$ the larger earthquakes were happening in Shawnee area or nearby. Figure 3 examining the Oklahoma state during fifty years and with more details in the period 2009-2015, the accumulation point for earthquakes with Magnitudes 4 - 6 are most on the Mississippi Lime, it is clearly a cluster of earthquakes in the region Oklahoma/Kansas, where is located the highest active quakes in the middle continent. The region was transformed through uplifting erosion and exposure to weathering and other geologic processes all before being buried again in subsequent periods. During those transformations in the area it was possible that fractures in the old shallow bed of ocean have been totally covered remaining dormant so far. However, with the advent of human activities in the area, slowly those fractures are awaking up and the magnitudes of the quakes are increasing year by year. Due to its brittle nature, the 'chat' has served as a reservoir rock and its weakness make it fragile for the stress and pressure applied in the region. We also observed the events happened at the depth $0-7 \mathrm{~km}$ and the same remarks apply for other states analyzed. It is a possibility of multiple subsurface faults, fractures in this region in deeper depths. Oklahoma/Kansas activity experimented last years a constant enhancement of earthquakes most at shallower depth 0 - 5 $\mathrm{km}$ with an increasing magnitude $\mathrm{M} \geq 3.5$ even though the number of waste water wells decreased last two years. It indicates an unknown subsurface fault in the region identified as Mississippi Lime, called as Chat, and it is not

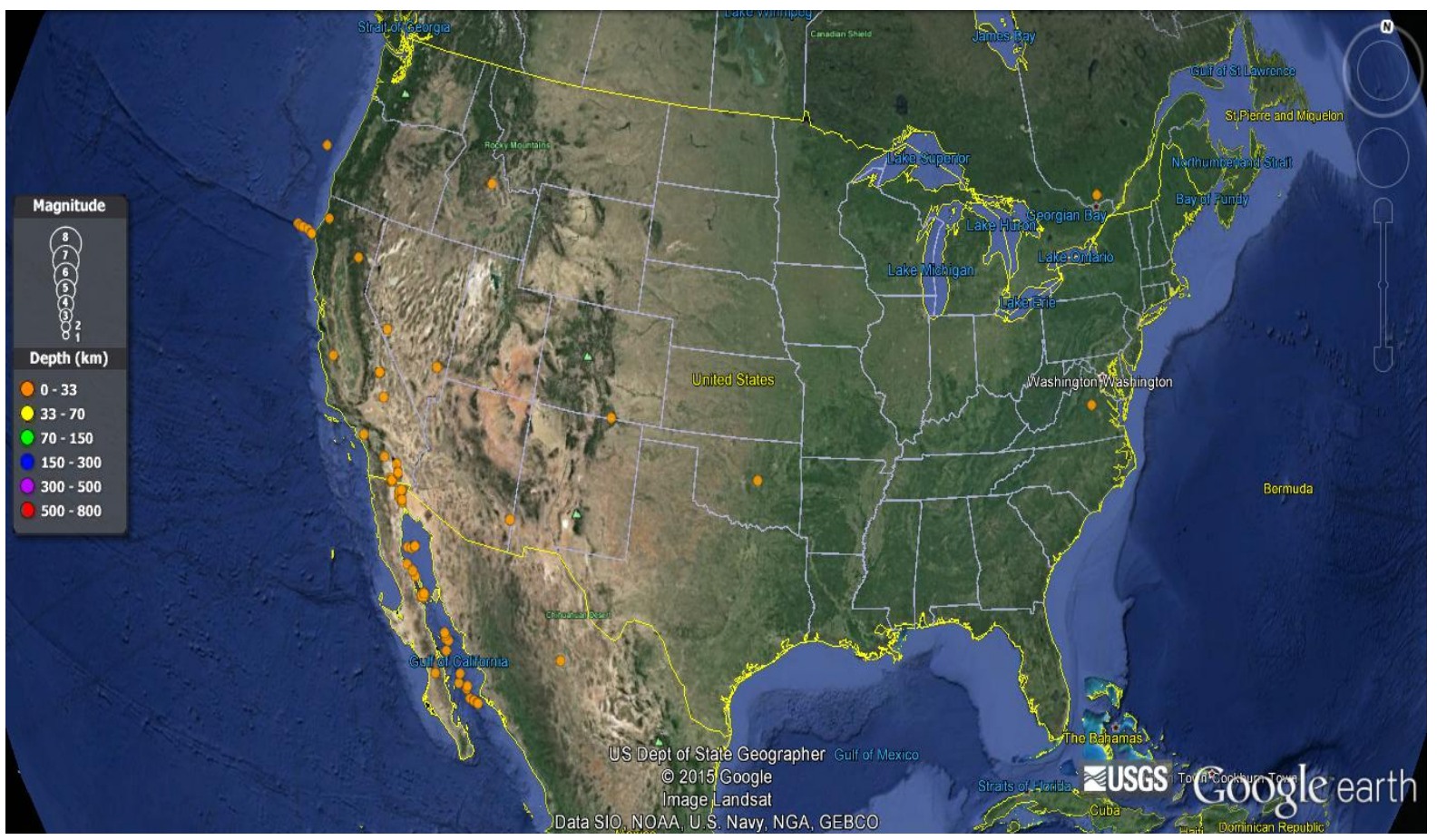

Figure 2. Showing the occurrences of earthquakes above $M \geq 5$ and below $M \leq 6$, with the same coordinates as Figure 1 in the period comprehending 2009-2015. 


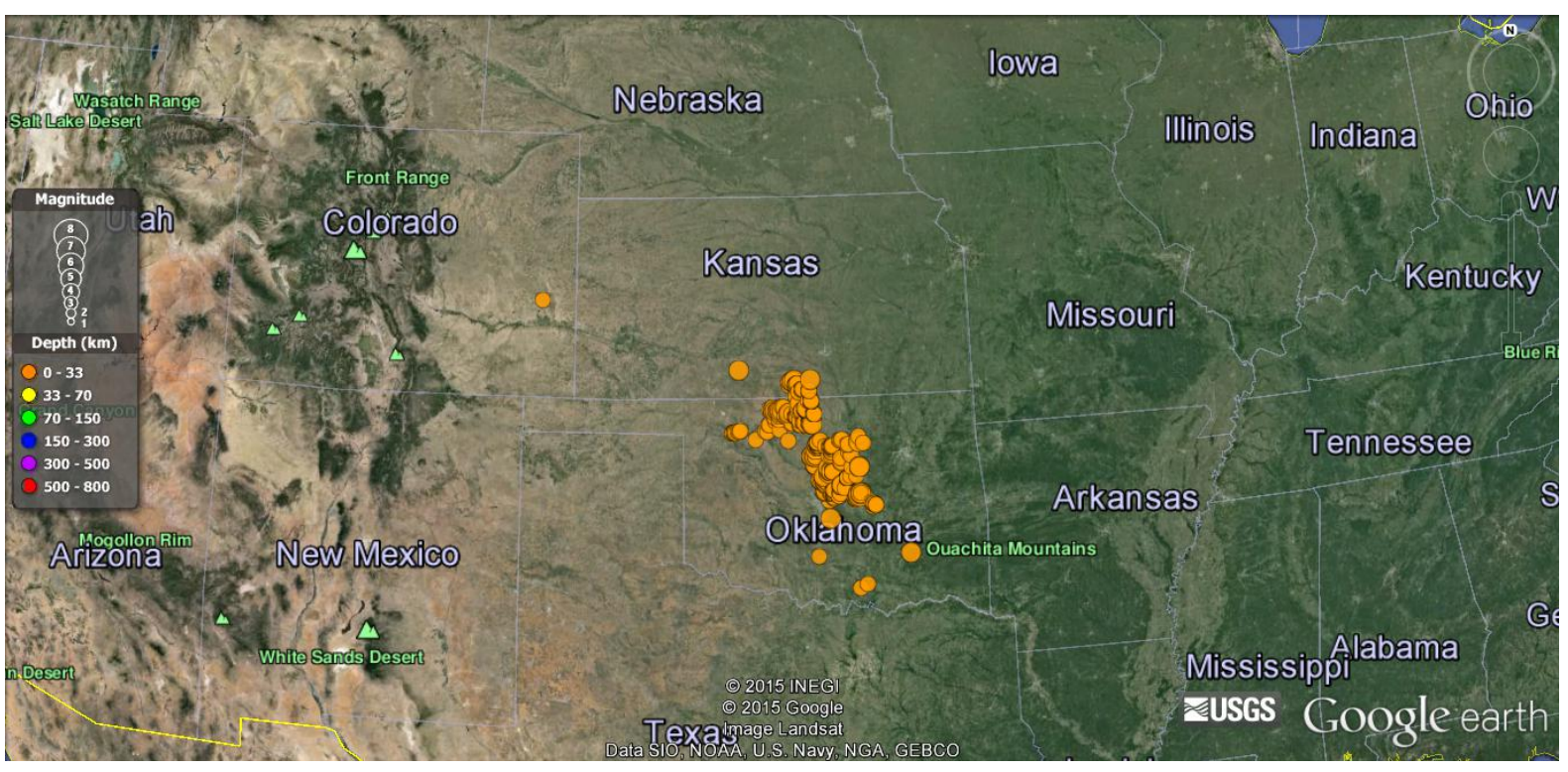

Figure 3. Oklahoma/Kansas period 2009-2015 M $\geq 3.5$. Observe a cluster of medium magnitude earthquakes at the boundary Oklahoma/Kansas.

considered shale. Last two years quakes $M \geq 4.0$ becoming more common at the same region, it is possible that dormant fractures are reactivated by the constant fracking and waste disposal wells in the region. Eventually, other places in Oklahoma are showing a surge of earthquakes with higher magnitude and it is possible that other dormant fractures are in this location.

The entire play is huge, encompassing 30 million acres and more than thousand wells have been drilled in 2013. The top of Mississippi is a major erosional unconformity across Kansas. These 'chart' reservoirs are very wide spread, in gross thickness from a few meters to $25 \mathrm{~m}$ thick and are heterogeneous in nature. This is caused in part through uplift, alteration, erosion and deposition of the original limestone commonly referred to as Mississippi Lime. Investigating those two events Oklahoma and Virginia, it is a suggestion due to the similarities on them first of all they are called unconventional reservoirs. Many waste water wells are located in this region pumping water in deeper depths, even though unpressurized water injected into sedimentary rocks causes even larger tremors however, but unlikely to happen above M 6. Why wells in this region cause the earth to shake and how large could it be? The explanation resemble in the earth's crust, in this region some place are thicker than other, the crust's thickness reaching $45 \mathrm{~km}$ and other places thinner.

The highest quake magnitude on Texas shale was M4, the first earthquake reported with such magnitude since 1980, was in 1997 and depth was $5 \mathrm{~km}$. It briskly enhanced in 2008 when 12 events were recorded in the depth 5 $\mathrm{km}$. The other locations on Texas with higher activity last years are Snyder between 2009 and 2015, when 57 earthquakes were informed starting in 2013 with only 3 events. Also San Antonio had an increasing in the frequency of events. In Figure 4 it is shown the number of events $M \geq 4$ happening in the entire land, only few places had such quakes. And Texas did not have cluster of events with such Magnitude.

Figure 5 displays the thickness variations on USA; the final contour map honors all available seismic refraction measurements for features with a dimension greater than 2 degrees. Those portions of the continental interior enclosed by the $40 \mathrm{~km}$ contour, and regions with crustal thickness of 45 to $50 \mathrm{~km}$ are found on all well surveyed continents (i.e., North and South America, Australia, and Eurasia). Continental crust with a thickness in excess of $50 \mathrm{~km}$ is exceedingly rare and accounts for less than $10 \%$ of the continental crust. These observations, now available on a global basis, provide important constraints on the evolution of the crust and sub-crustal lithosphere. The old Appalachian Mountains form a highland area in the eastern part of the continent, while the younger Rocky Mountains form a higher more rugged frame in the west. Between the two are the lower, flatter physiographic provinces: the Canadian Shield, the interior plains and the Great Plains.

The higher crust thickness is situated in the middle country, $45 \mathrm{~km}$ or more. It looks like the thickness moving from West to East with the thicker surface in the middle. Clearly is a relationship linking magnitude of earthquakes and crustal surface apparently the higher magnitude does not affect the intensity of earthquake damage in 


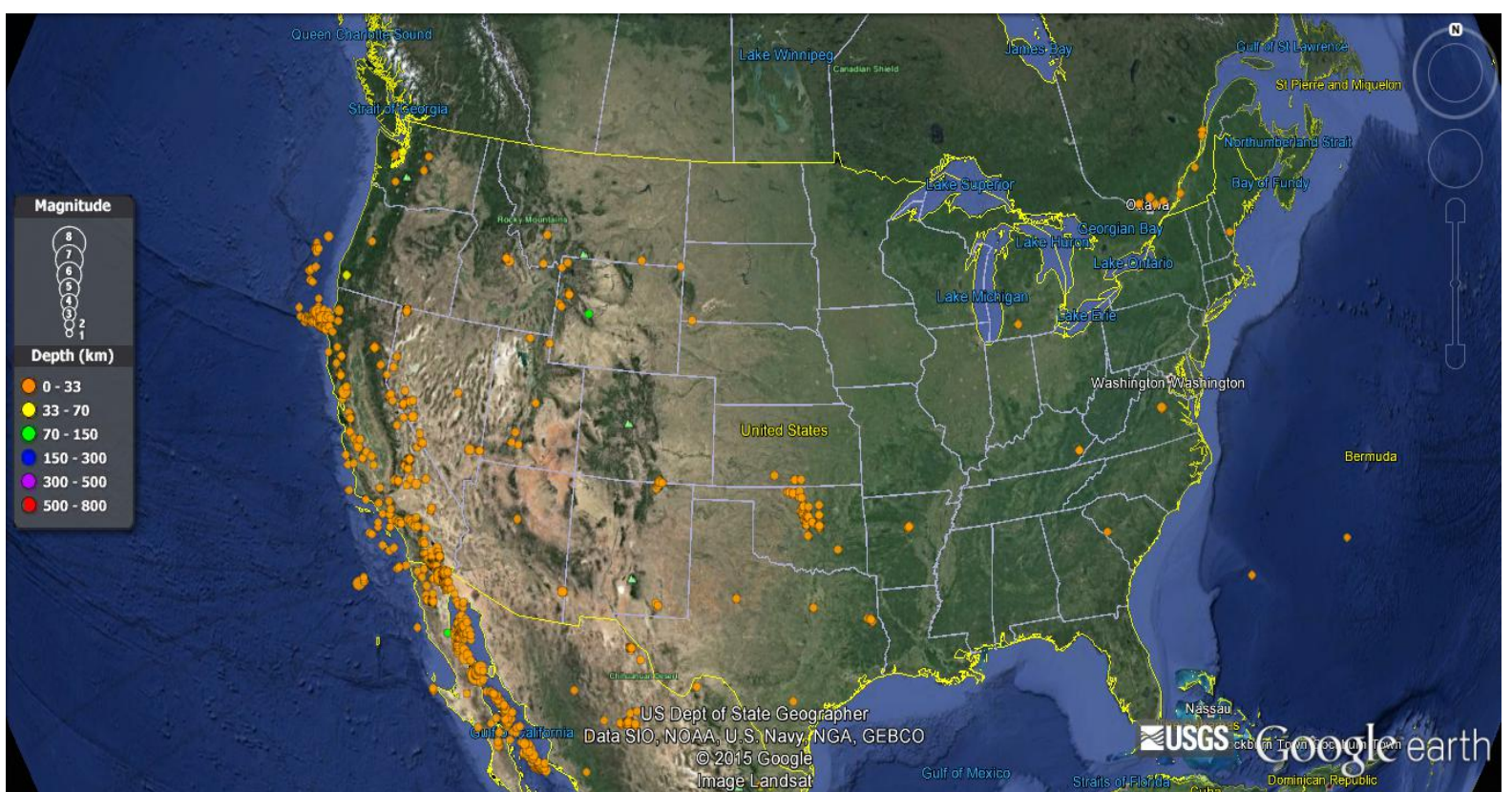

Figure 4. The picture shows the entire USA, period 2009-2015 with earthquakes $M \geq 4$. Only some locations inside of the country contributed with such events.

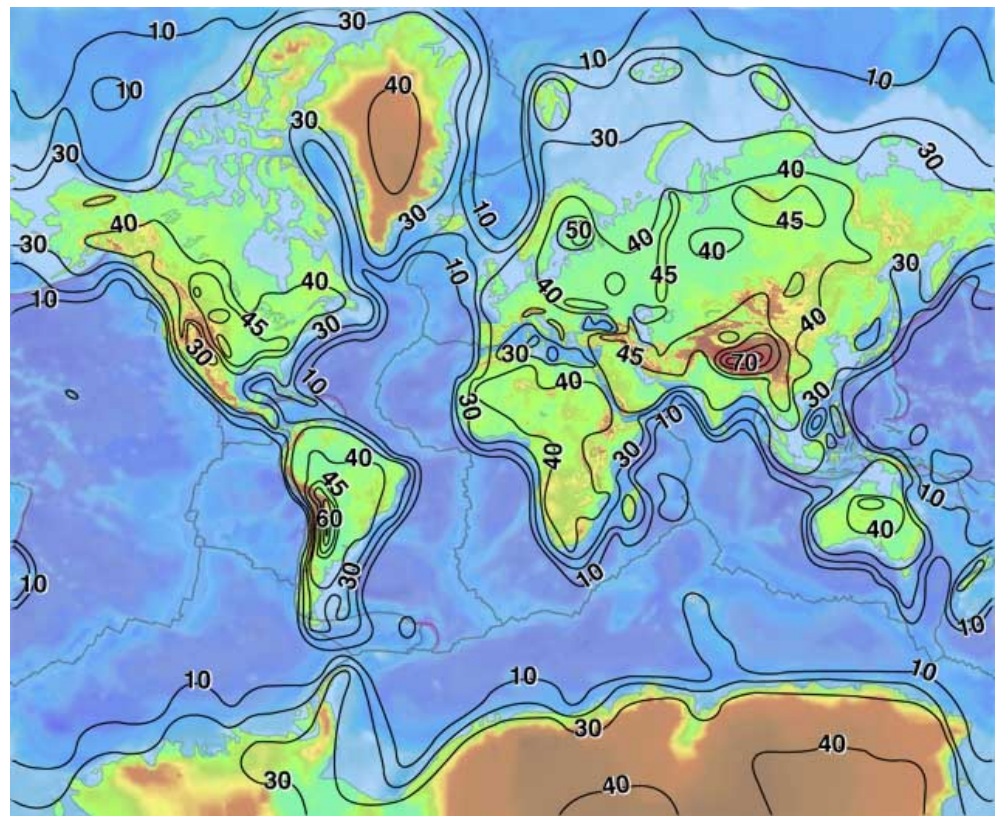

Figure 5. This contour map of the thickness of the Earth's crust was developed from the CRUST 5.1 model. The contour interval is $10 \mathrm{~km}$; we also include the $45 \mathrm{~km}$ contour for greater detail on the continents (Appendix A).

the East side. Earthquakes at the eastern side are more destructive and their intensity dangerous than at the western side but is a rare event earthquakes with higher magnitudes at the east side of USA.

Let reminds the tectonic geomorphology on the continent. Western side is a boundary of the tectonic plate convergent, with a late Cenozoic rifting orogeny. Near the Pacific Ocean crustal thickness is thinner as $15 \mathrm{~km}$. A Mesozoic orogeny formation divided the feature from a Platform created by late glaciers. At eastern side Platform make boundaries with several different formations shield, Paleozoic orogeny, Coastal Plain and a Continental margin. Despite of diversity at the eastern formation at the eastern side of the Platform the crustal layer 
has higher thickness, affecting the frequency and magnitude of earthquakes at this side. Our study found that locations with higher crust thickness generating lower magnitude events, small earthquakes have increased numerically in specific areas presenting swarm events as we talk later.

Some exceptions as in Nevada State which has a swarm of events, classified as nuclear explosions, by USGS including the larger one M6.4 in 1974. Table 1 is constructed with the states which have been decreasing number of quakes during last seven years, in both Tables all magnitude events were taken. It would give an idea about the states seismologically active or not without pre conditions.

Florida, Wisconsin and Louisiana (not in the Table) had no occurrence of earthquakes, only Louisiana have wells among them 3000 are waste disposal wells of class II. The states into the Great Plains showed fewer or smaller magnitude events as North/South Dakota, and Nebraska. Michigan is one of the states supposed do not have wells however, they have coal bed methane exploration near the Lake and shows seismological small activity as observed in Table 1, however the events disappeared since two years ago, but the seismic activity has been always superficial $(0 \mathrm{~km})$.

Table 2 displayed states with an enhancing of earthquakes in the period 1965-2015 some states as Kansas had no event reported until 2009. It is an important result because Oklahoma/Kansas border nowadays it is the most active area in the middle country in 2015. Besides these two states another ones are also increasing events they are at the west side Arizona, California, Colorado, Idaho, Nevada, Oregon, and at east Arkansas, Missouri, Montana, Wyoming, Utah. At the Eastern side, we have Arkansas, Missouri, Tennessee and Central, Oklahoma, Kansas, Texas. Some of those states do not have fracking for oil and gas, but they have disposal wells for gas methane exploration. The characteristic of those events they are superficial.

Let us have a look in 2010 (when many states started to add waste water wells), there are three states suddenly increased number of shakes, California, Wyoming and Oklahoma. We found "fracktracker" catalog which provided a roughly number of active wells (oil/gas) around the country and divided them in "known" and "unknown" slat. Nowadays there sort of 300,000 wells in Texas with several different slants. Oklahoma on the other hand reported only 12,727 wells. Recently both states provided the info about the waste disposal wells there are circa of 50,000 in Texas and 7000 in Oklahoma, from them some are supposed to be linked for earthquakes. The difference Oklahoma/Kansas and Texas cluster events is the lower magnitude and frequency in Texas comparing to Oklahoma, even though Texas have a higher number of class II wells. Here it is the first clue to the earth's crust variation, the thicker crust less events.

\section{Results Discussion}

The first part of our research search for the period variations on earthquakes by location, magnitude and depth.

Table 1. The table shown states with decrease number earthquakes last years. Some of them refused the lodge of horizontal wells or unconventional drill; some are located on the Great Plains.

\begin{tabular}{ccccccc}
\hline States & 2009 & 2010 & 2011 & 2012 & 2013 & 2014 \\
\hline Alabama & 7 & 5 & 6 & 3 & 6 & 5 \\
Kentucky & 1 & 0 & 1 & 7 & 3 & 6 \\
Michigan & 17 & 13 & 5 & 3 & 1 & 0 \\
Minnnesota & 6 & 20 & 8 & 1 & 2 & 0 \\
Mississippi & 0 & 3 & 0 & 0 & 0 & 0 \\
Nebraska & 0 & 3 & 1 & 1 & 0 & 1 \\
North Dakota & 0 & 0 & 0 & 1 & 0 & 0 \\
Pennsylvania & 9 & 3 & 0 & 0 & 0 & 1 \\
South Dakota & 0 & 0 & 3 & 1 & 1 & 1 \\
Virginia & 3 & 3 & 48 & 17 & 2 & 6 \\
Wisconsin & 0 & 0 & 0 & 1 & 0 & 0 \\
\hline
\end{tabular}


Table 2. It shows in average number which states earthquakes events increased last years. Observe the 2010 column, the states California, Oklahoma, Wyoming.

\begin{tabular}{|c|c|c|c|c|c|c|}
\hline States & 2009 & 2010 & 2011 & 2012 & 2013 & 2014 \\
\hline Arizona & 8 & 11 & 10 & 10 & 10 & 64 \\
\hline Arkansas & 17 & 72 & 176 & 9 & 176 & 124 \\
\hline California & 530 & 2258 & 858 & 535 & 389 & 410 \\
\hline Colorado & 30 & 13 & 53 & 29 & 40 & 49 \\
\hline Idaho & 39 & 37 & 37 & 31 & 71 & 177 \\
\hline Kansas & $\mathbf{0}$ & 1 & 0 & $\mathbf{0}$ & 7 & 148 \\
\hline Missouri & 9 & 11 & 10 & 13 & 15 & 47 \\
\hline Montana & 36 & 30 & 48 & 32 & 27 & 54 \\
\hline Nevada & 54 & 80 & 157 & 52 & 101 & 1291 \\
\hline Oklahoma & 50 & 187 & 165 & 98 & 334 & 2140 \\
\hline Oregon & 24 & 44 & 37 & 28 & 23 & 81 \\
\hline Tennesse & 11 & 5 & 7 & 14 & 14 & 39 \\
\hline Texas & 15 & 17 & 39 & 32 & 66 & 52 \\
\hline Utah & 41 & 54 & 60 & 45 & 38 & 111 \\
\hline Wyoming & 176 & 211 & 171 & 102 & 83 & 172 \\
\hline
\end{tabular}

We also could link the increasing number of earthquakes in some regions with the variations of the earth's crust thickness. The magnitude of the clusters in a region is depending directly from the thickness of the crust. The regions presented clusters in various magnitudes for example, clusters magnitude $M \geq 4$ are common in Oklahoma, but in Texas the swarm is $\mathrm{M} \geq 3.5$ it is the same in others states analyzed as Colorado and the states around New Madrid fault. In Georgia and Maine the clusters have smaller magnitudes as $M \geq 2$. Those observations as different kinds of human activity in each area observed seems to corroborated our initial observations in Oklahoma/Kansas, depending the region explored by fracking, waste water wells, nuclear explosions, mining are reaching subsurface faults dormant so far. As our analysis bellow in the states with fracking or not, showed several states that did not have gas/oil wells however the earthquakes increased in minor magnitudes. Therefore, it is an indication that dormant faults in several intraplate regions have been awaken.

Analyzing 51 states from the Frac Focus and EPA in 2014, 15 states declared do not have wells, among them Georgia and Maine, 18 increased the number of wells, 6 decreased the number of wells. Now, we compared this information with the increase of earthquakes. Six states enhanced small earthquakes, even though they did not have any fracking. Most states also increased the number of disposal wells. In the same period Florida reported 55 wells, (particularly they were 6 directional, 11 horizontal, and 38 vertical) but no earthquake was recorded since 1965. Louisiana during the period 1965-2015 had no earthquakes, however, in this state in 2014 there were reported circa of 64,343 wells with different slants. Louisiana has 3740 disposal wells.

\section{Arkansas, Missouri, Tennesse-New Madrid Fault Complex}

Arkansas, Missouri, and Tennessee are part of the New Madrid fault complex. Let starts with Arkansas, the average of earthquakes in this area was very low. Since 2009 it increased, in 2010 an anomaly has occurred and reported two hundred earthquakes. The biggest earthquake in the region was near of Greenbrier/Guy were the biggest earthquake magnitude M 4.8 occurred in 2011, in the period 2009-2015 a total of 314 quakes hit the state with several swarm in the region mentioned. This location has waste water disposal wells most for the coalbed methane extraction.

Next two states New Madrid fault are Tennessee and Missouri, both have increased intensely the earthquakes 
activity since 2010, several swarms as the border Missouri/Tennessee, northeastern of Tennessee. Missouri potentially has large quantities of "unconventional" energy resources that include: coalbed methane, oil sand and oil shale. The place in Missouri/Tennessee that contributed more for the enhancement of small earthquakes was Mississippi embayment. In Tennessee were detected cluster events on the Chattanooga region. In these three states the clusters presented the $\mathrm{M} \geq 3.5$ in all the regions studied. To finalize our analysis, Arkansas, Missouri and Tennessee, displayed a pattern with cluster of small earthquakes with epicenter bellow $8 \mathrm{~km}$ and spread in different areas on these States. It consistently happened on the States neighbors to the New Madrid fault.

\section{Colorado Earthquakes}

The next is Colorado on the period 1965-2015, shown that events started on 1973 with an explosion reported in East Tavputs Plateau with unknown origin. This location registered an average of 477 earthquakes, depth 0-7 $\mathrm{km}$ special located at the Paonia region connected with rock burst or coal burst at this time, what leads for the waste water well . The first detection officially linked to rock burst was reported in 2001 in the West Elk Mountain. Since 2009 there is an enhancement in the events. It is impossible to distinguish if there is any natural occurrence because it is not close with faults, has a high crustal thickness on this location and there are many earthquakes clusters. Other point with rise of occurrences is located in Trinidad, near Sangre de Cristo Mountain. Trinidad is situated on Raton Basin, at the foothills of the Rocky Mountain. Colorado also is part of the four corner region, the larger US methane anomaly, and highly methane exploration is being done. The sedimentary beds are Paleozoic, Mesozoic, and Paleogene age. The eastern part of the basin, the sedimentary section is covered by flours of basalt of Miocene age as observed in Virginia where is located a coal-bed methane field in Richmond [9].

\section{Texas Activity}

Presently Texas has a larger number of wells compared to Oklahoma but the number of earthquakes $\mathrm{M} \geq 4$ (Texas) are almost nonexistent. There are more than 50,000 disposal wells in Texas servicing more than 216,000 active drilling wells, according to Railroad Commission; each well uses about 4.5 million gallons of chemicallaced water. Therefore, the actual theory for the induced or triggered earthquakes needed to be revised, new understanding of the tectonics and the geological formations in the drilling locations and earthquakes.

The domed rocks of the Central Texas Uplift form topography different from that of the Black Hills. Erosion of abroad, uplifted dome here has exposed a core of old granites, gneisses, and schists, as in the Black Hills, but in the Central Texas Uplift, erosion has produced a topographic basin, rather than high peaks and spires, on the old rocks of the central area. A low plateau surface dissected into rounded ridges and narrow valleys slopes gently eastward from the edge of the central area to an escarpment at the Balcones fault zone, which determines the eastern edge of the Great Plains here.

The cutting action of streams, modified or controlled in part by differences in hardness of the rock layers, has been responsible for the landforms of the Central Texas Uplift. Weathering of the old core rocks has softened them sufficiently to permit deeper erosion of the central area, and solution of limestone by ground water has formed such features as Longhorn Caverns, 11 miles southwest of Burnet, Texas.

Texas had three important regions with the increasing of earthquakes one was in Dallas since 2009, the main characteristic of those earthquakes is the depth location reported as $5 \mathrm{~km}$. Only on 2015 started earthquakes with depth $\geq 8 \mathrm{~km}$. This activity has a possibility to be attached for the 50,000 wells in the region. In average the earthquakes are $\geq 3.5$. The depth of $5 \mathrm{~km}$ is recurrent for almost all the swarm quakes whole state.

Still working on Texas State, there was another cluster of earthquakes located in Snyder. It was discovered some years ago a new shale in Snyder called Cline shale, it is a Permian basin comprised of three parts: the eastern Midland Basin, the central basin Platform and the western Delaware basin. This area is covered by black shale, organic -rich, deep water materials that would become source rocks in later geologic intervals this material is similar as the Mississippi lime reported in Oklahoma. The records provided about 57 small earthquakes up to a depth $7 \mathrm{~km}$. In this particular area of Texas, the events had increased 2010-2014. All in all, there are 7000 waste water wells officially reported in Texas and it covers most of the state. However, the quakes activity was observed more into the three areas specified. Resuming earthquakes in these regions studied had the following behavior, near New Madrid fault States, events are deeper, however the magnitude of the cluster started at $\mathrm{M} \geq$ 3.5 with small occurrence of earthquake $M \geq 4$. In the states far from New Madrid as for example, Texas, the 
events depth is shallower, it is common to observe earthquakes $0-5 \mathrm{~km}$.

\section{Oklahoma and Virginia Activity}

A brief analysis in Oklahoma showed there were no event $M \geq 4.0$ in 2009. Since, 2011 cluster of earthquakes has been reported in the Mississippi Lime with $M \geq 4.0$, in a shallower depth $0-6 \mathrm{~km}$, even though some reports tell that the number of disposal wells declined. Those evidences converged in a possible link between the intensification of the exploration of Mississippi lime area and the unconformities of the crustal surface where the drilling is hitting on unknown shallow dormant fractures, normally observed at the depth of $5 \mathrm{~km}$ below the surface. Also this location is plenty of waste water disposal wells injected in technical depth of $1,5 \mathrm{~km}$.

Virginia also had an earthquake in 2011; magnitude 5.7, the region has seldom large earthquakes. In 2009, this place added waste water wells due to exploitation of coal bed methane needed to the dispose of contaminate water coming from the well. As mentioned before this method of dispose water increase the pressure underground and depending from the geological characteristics will trigger quakes with higher magnitude, depth and frequency. The central continent is uneven there are different thicknesses with diverse shale formations; Mississippi Lime has a unique structure which is responsible for the highest magnitude quakes nowadays in central USA. Any model address to find out the reasons for the enhancement of earthquakes in one region, must consider the irregular sub surfaces in the region analyzed, and the possibility of new fractures, faults. The shale composition has different response under the same stress. States that reported to not have shale or wells as Georgia and Maine showed clusters with magnitude $M \geq 2$. Nevertheless, some non-official sites reported mining in Georgia and Maine. There is also a possibility they have waste disposal but not deeper as in other states with oil/gas exploration. Big earthquakes in Nevada period 1970-1980 were due to nuclear underground explosions. After 2009 swam events at the western side of Nevada, an enhancement of events $M \geq 4$ at California/Nevada borders, at the moment they reported only Class V wells in the area of such earthquakes.

\section{Correlations Earth's Crust and Earthquakes in USA}

A brief analysis of regions that increased seismicity last few years provided the following conclusions: a) prior to 2009, the regions targeted had no history or lower seismicity. b) The depth of quakes depends of the location they surge, near a preexistent central fault as New Madrid, they occurred in profounder depths, and lower magnitudes. c) The magnitude of the cluster of earthquakes also depended from the location. The states presented the following clusters magnitudes, California quakes swarm magnitude $M \geq 6.0$, South Carolina and Oklahoma clusters around magnitude $M \geq 4.0$. Minnesota, Colorado, Wyoming, Arizona, Arkansas, Missouri, Tennessee, West Virginia quakes swarm $M \geq 3.5$. New Mexico, Virginia swarms $M \geq 3.0$. Finally, the lowest ones in magnitude is Maine and Georgia with quake clusters $M \geq 2.0$. All those states presented some areas with cluster of earthquakes with particular magnitude in each region, what lead us to the conclusion that depending of the underground tectonics some areas has higher magnitude swarm earthquakes than others. The anomaly observed in Oklahoma looks that the intense exploration in the place ignited a subsurface fault or fracture long time dormant. The shale compositions in those regions with higher activity $(M \geq 4.0)$ overall shared a black, organic-marine formation as in the mid -US.

The discrepancies in the Earth's crust thicknesses, make locations respond differently in intensity, magnitude and epicenter position. It would explain why some places have deep waste water disposal with intense quakes response and others are uneventful. Once a fracture is awake it will keep increase the magnitude and the frequency of the occurrences even though the well is inactive. All in all, small/medium earthquakes during the period 2009-2014 in several locations of the USA is due to different human activities.

Those actions will influence the ground and will respond to these interferences is dependent most of the thickness of the earth's crust in the region analyzed. The awake of dormant subsurface faults or fractures becoming active will change the increase of magnitude events. So far, the western side contributed with the highest level of magnitude events during the period in analysis some places reaching M6 or more as the ones observed in Nevada thirty years ago with nuclear experiments. Those events nowadays decayed in number, magnitude (M $\geq 4$ ) and moved the location southern to western Nevada. The western side is the youngest and thinner crust in the continent therefore it also contributed for the higher magnitude quakes in the region nevertheless they are natural or triggered by human activity. The midcontinent is the thickest surface and the incidence of earthquakes is smaller. However, with the a possible awakening of a dormant fracture in Oklahoma/Kansas last years it have 
increased the occurrence of events in magnitude, and frequency.

\section{Conclusion}

Our research concludes that essentially, earthquakes have been increased overall in USA, due to different anthropogenic reasons. Some of them are involuntary as the disposal wells which hit different dormant fractures or faults unknown so far. We also conclude that many points of accumulation of increased quakes having a common depth around $5 \mathrm{~km}$ indicated in such region must have a subsurface tectonic structure that allows the surge of earthquake.

\section{Acknowledgements}

I am thankful to my adviser in Japan, Dr. S. Hamada, from Nihon University, Tokyo, Japan, whom was my doctorate adviser period 1986/1988, to Mr. Charles W. Hagen who corrected some of English and, Dr. M. Hamburger who helped me with important suggestions along this research and the valuable recommendations from the anonymous referee.

\section{References}

[1] Ellsworth, W.L. (2013) Injection-Induced Earthquakes. Science, 341. http://dx.doi.org/10.1126/science.1225942

[2] McGarr, A. (2014) Maximum Magnitude Earthquakes Induced by Fluid Injection. Journal of Geophysical Research: Solid Earth, 119, 1008-1019. http://dx.doi.org/10.1002/2013JB010597

[3] McGarr, A. (1999) On Relating Apparent Stress to the Stress Causing Earthquake Fault Slip. Journal of Geophysical Research, 104, 3003-3011.

[4] Anderson, J.G., Tibuleac, I., Anooshehpoor, A., Biasi, G., Smith, K. and von Seggern, D. (2009) Exceptional Ground Motions Recorded during the 26 April 2008 Mw 5.0 Earthquake in Mogul, Nevada. Bulletin of the Seismological Society of America (Seismological Society of America), 99, 3475-3486. http://dx.doi.org/10.1785/0120080352

[5] Hennings, P., Allwardt, P., Paul, P., Zahm, C., Reid Jr., R., Alley, H., Kirschner, R., Lee, B. and Hough, E. (2011) Relationship between Fractures, Fault Zones, Stress, and Reservoir Productivity in the Suban Gas Field, Sumatra, Indonesia. AAPG Bulletin, 96, 753-772.

[6] Sandvol, E., Seber, D., Sandvol, C., Brindisi, C. and Barazangi, M. (2001) Regional GIS Databases in Support of CTBT Monitoring. 23 Seismic Research Review, Worldwide Monitoring of Nuclear Explosions, 2-5 October.

[7] Langlois, K. (2014) Manmade Quakes Shakes the Southwest. High Country News.

[8] Rubinstein, J.L., Ellsworth, W., McGarr, A. and Benz, H.M. (2014) The 2001-Present Induced Earthquake Sequence in the Raton Basin of Northern New Mexico and Southern Colorado. Bulletin of Seismological Society of America, 104, 1-20. http://dx.doi.org/10.1785/0120140009

[9] USGS (2011) Assessment of Undiscovered Oil and Gas Resources of the East Coast Mesozoic Basins of the Piedmont, Blue Ridge Thrust Belt, Atlantic Coastal Plain, and New England Provinces. 


\section{Appendix A: Data Information for Tables and Figures}

Indiana Geological Survey

Kentucky Geological Survey

Ohio Geological Survey

Oklahoma Geological Survey

Waste water injection wells http:/www.texastribune.org/series/water-for-fracking/map/

Frac Focus data-fracking by number: Key impacts of dirty drilling at the stated and National Level-2014

EPA: Energy Protection Agency

EIA: Energy Information Administration

USGS http://earthquake.usgs.gov/earthquakes/recenteqsww/Quakes/quakes_all.php

IRIS http://ds.iris.edu/wilber3/find event

http://www.geomore.com/porosity-and-permeability-2/

NGDC/NOAA http://www.ngdc.noaa.gov/hazard/

http://www.virginiaplaces.org/geology/naturalgasresources.html

Figure 5 http://earthquake.usgs.gov/data/crust/ 